\title{
Vehicle Fuel Economy Improvement through Vehicle Optimization in 1-D Simulation Cycle towards Energy Efficient Vehicle (EEV)
}

\section{Shaiful Fadzil Zainal Abidin ${ }^{1}$, Amir Khalid ${ }^{\text {1*}}$, Siti Nor Zulaikha Shafai@Shafie ${ }^{1}$, Izzarief Zahari ${ }^{2}$, Rifqi Irzuan Abdul Jalal ${ }^{3}$}

${ }^{1}$ Automotive and Combustion Synergies Technology Group, Faculty of Engineering Technology, Universiti Tun Hussein Onn Malaysia, 84600 Pagoh, Johor, MALAYSIA

${ }^{2}$ Perusahaan Otomobil Nasional Sdn. Bhd. Hicom Industrial Estate, 47600 Shah Alam, Selangor, MALAYSIA

${ }^{3}$ Universiti Kuala Lumpur - Malaysia France Institute (UniKL MFI), Section 14, Jalan Damai, Seksyen 14, 43650 Bandar Baru Bangi, Selangor, MALAYSIA

*Corresponding Author

DOI: https://doi.org/10.30880/ijie.2020.12.08.035

Received 16 January 2020; Accepted 17 September 2020; Available online 30 August 2020

\begin{abstract}
The high average of fuel consumption in vehicle for ASEAN countries compared to global average has led to the establishment of Energy Efficient Vehicle (EEV) by National Automotive Policy (NAP) 2014. The current PROTON Saga 1.3L 4-speed automatic transmission (4-AT) recorded $6.80 \mathrm{~L} / 100 \mathrm{~km}$. Meanwhile, the target setting for fleet average fuel consumption for the same segment according to NAP 2014 is $6.0 \mathrm{~L} / 100 \mathrm{~km}$. Hence, it is crucial for manufacturers to reduce the vehicle fuel consumption to stays competitive in the market and also to support the ASEAN emission legislation. The objectives of this research are to develop a 1-Dimensional 4-AT vehicle physics model for fuel economy and performance analysis as well as to further understand the sensitivity of vehicle configuration and fuel-saving technologies to achieve the product target and legislation requirements. The PROTON Saga 1.3L 4-AT vehicle model which is a B-Segment passenger vehicle will be developed using 1Dimensional simulation software. The correlation between the base vehicle model and actual vehicle model is $0.14 \%$ for fuel consumption and $2.22 \%$ for $0-100 \mathrm{~km} / \mathrm{h}$, since the value is less than $4 \%$, the vehicle model can be concluded as valid and authentic. All the data and engine maps used in this research are provided by PROTON Engineering Department to support the accuracy of findings. For each parameter considered in this research, the optimization was performed in simulation where it begins from the current vehicle engine configuration and then applying each parameter at each step until the anticipated configuration of vehicle has achieved. The parameters involved in this research are vehicle weight, aerodynamic, rolling resistance, final gear ratio, and idle speed. Stop start system was used as an advanced alternative way to mitigate the fuel consumption since it is cost consuming. The fuel consumption for an optimized model is $6.01 \mathrm{~L} / 100 \mathrm{~km}$ with $0.17 \%$ difference with the real target which is $6.0 \mathrm{~L} / 100 \mathrm{~km}$. The current vehicle model fuel consumption is $6.80 \mathrm{~L} / 100 \mathrm{~km}$, thus, it has been successfully reduced to $6.01 \mathrm{~L} / 100 \mathrm{~km}$ which is equivalent to $11.62 \%$ without implementing stop start system and $25.03 \%$ with the implementation of stop start system. It seems that the beneficial to examine various possible solution concepts, and to establish understanding on the effectiveness and synergies between powertrain technologies and vehicle design in reducing the overall fuel consumption ad emission.
\end{abstract}

Keywords: Fuel consumption, emission, vehicle optimization, Energy Efficient Vehicle 


\section{Introduction}

In these recent decades, the transportation industry depends primarily on petroleum fuels, with total usage of 88.13 million barrels a day worldwide. This dependence on petroleum-based fuel presents both immediate and long - term challenges such as emissions and lack of fuels. Transportation emissions itself has contributed an amount of $23 \%$ to the global anthropogenic emissions [1-4]. In ASEAN, the average fuel consumption in 2015 was between $7.7 \mathrm{~L} / 100 \mathrm{~km}$ for the Philippines and $6.6 \mathrm{~L} / 100 \mathrm{~km}$ for Malaysia which is quite higher than the world average fuel economy which is about $7.0 \mathrm{~L} / 100 \mathrm{~km}$ [5]. To cope with this situation, Energy Efficient Vehicle (EEV) that has been introduced through National Automotive Policy 2014 has become a perfect solution to improve the fuel economy and as a reduction of emissions to meet the future emission legislation. Table 1 shows the EEV Technical Specification for Fuel Consumption according to their segments which will be used as a standard. It is determined based on international benchmarking across developed countries (Europe, United States of America, China, Japan, South Korea, Thailand and Taiwan) [6]. Table 1 depicted that Proton Saga 1.3L 4-speed automatic transmission (4-AT), which weights $1075 \mathrm{~kg}$ is classified as a B-Segment car. Therefore, the fuel consumption that should be followed by this vehicle is $6.0 \mathrm{~L} / 100 \mathrm{~km}$.

Table 1 - EEV technical specification for fuel consumption [3]

\begin{tabular}{cccc}
\hline SEGMENT & DESCRIPTION & $\begin{array}{c}\text { KERB } \\
\text { WEIGHT }(\mathrm{KG})\end{array}$ & $\begin{array}{c}\text { FUEL } \\
\text { CONSUMPTION } \\
(\mathrm{L} / 100 \mathrm{KM})\end{array}$ \\
\hline $\mathrm{A}$ & Micro Car & $<800$ & 4.5 \\
& City Car & $801-1,000$ & 5.0 \\
$\mathrm{~B}$ & Super Mini Car & $1,001-1,250$ & 6.0 \\
$\mathrm{C}$ & Small Family & $1,251-1,400$ & 6.5 \\
& Car & $1,401-1,550$ & 7.0 \\
$\mathrm{D}$ & Large Family Car & & \\
& Compact Executive Car & $1,550-1,800$ & 9.5 \\
$\mathrm{E}$ & Executive Car & $1,801-2,050$ & 11.0 \\
$\mathrm{~F}$ & Luxury Car & $2,051-2,350$ & 11.5 \\
$\mathrm{~J}$ & Large 4x4 & $2,351-2,500$ & 12.0 \\
Others & Others & & \\
\hline
\end{tabular}

Source: (B. Tol, 2014)

\subsection{Power Requirement/Driving Resistance}

Nowadays, car manufacturers and researchers are actively developing an EEV to reduce the fuel consumption. Therefore, one of the principal objectives of powertrain development is to ensure excellent driving dynamics at optimal fuel consumption. For a vehicle to accelerate, decelerate or even to drive at a constant velocity, it means that the vehicle needs to overcome the resistance. The resistances are made up of wheel resistance, air resistance, gradient resistance and acceleration resistance [7]. $F_{R}$ has designated the wheel resistance (rolling resistance force), $F_{S t}$ represents the gradient resistance (as slope resistance force on a slope with the angle $\alpha$ ) $F_{L}$ represent the air drag resistance. Meanwhile, $F_{a}$ represents acceleration resistance [8].

Rolling resistance is defined as the energy dissipated by the tire per unit of distance [9]. Therefore, the more energy is consumed by a moving vehicle, the higher the cost of transport and the greater emissions of $\mathrm{CO} 2$ as well as other toxic compounds is [10]. The rolling resistance for a vehicle with a mass $\left(m_{F}\right)$, is considered equal to the wheel resistance $F_{R}$, the equation is given by

$$
F_{R}=f_{R} m_{F} g \cos \propto_{S t}
$$

The gradient angle $\alpha \mathrm{St}$ can be ignored on regular journeys with gradients/downhill slopes of less than $10 \%$. With a gradient of $10 \%, \alpha_{S t} \approx 5.7^{\circ}$ and thus $\cos \alpha_{S t} \approx 1$ [7]. The rolling resistance coefficient is $F_{R}$ varies depends on the road conditions. It is important to reduce rolling resistance since $30 \%$ reduction of tyre rolling resistance can improve the fuel efficiency with an amount of $4 \%$ [11].

The air flows around the moving vehicle and through it for purposes of cooling and ventilation which creates aerodynamic. The value of aerodynamic drag is varying according to the types of vehicle body shapes. A research review stated that a $15 \%$ reduction in aerodynamic drag at highway speed of $55 \mathrm{mph}$ could result in about $5-7 \%$ in fuelsaving [12]. The aerodynamic drag could be expressed in an equation as, 


$$
F_{L}=\frac{1}{2} \rho_{L} C_{W} A V^{2}
$$

Where $A$ is the maximum vehicle cross-section meanwhile $C_{W}$ is the drag coefficient. $V$ is the airflow rate, which has a positive sign when this component is opposite to the vehicle speed and a negative sign when it is in the same direction as vehicle speed [13]. At an air pressure of 1.013 bar, relative air humidity of $60 \%$ and a temperature of $20^{\circ} \mathrm{C}$ the air density $P_{L} 1.199 \mathrm{~kg} / \mathrm{m} 3[4]$.

When a vehicle goes up or down a hill or slope, the weight of the vehicle produces a component that is always directed in the downward direction. The component either opposes the forward motion or helps the forward motion. Gradient resistance can be expressed as,

$$
F_{S t}=m_{F} g \sin \propto_{S t}
$$

In the case of (longitudinal) dynamic driving manoeuvres, a portion of the power delivered by the engine is required for acceleration of the power train masses, which is known as acceleration resistance. It is given by

$$
F_{a}=\lambda m_{F} a
$$

Where $\lambda$ is a rotational inertia coefficient, which expresses the proportion of the total mass that is rotational. The value of $\lambda$ is a difference according to the gear. For example, the values for trucks crawler are gear: $\lambda \approx 10,1$ st gear: $\lambda \approx 3$, direct gear: $\lambda \approx 1.1$.

Therefore, all the forces involved in moving the vehicle could be summarize as traction force, $F_{T}$ by using the traction force equation. The traction equation is given as below:

$$
F_{T}=F_{R}+F_{L}+F_{S t}+F_{a}
$$

However, with a steady-state motion $(a=0)$ and the approximations mentioned $\left(\cos \propto_{S t} \approx 1\right.$ and $\left.\sin \propto_{S t} \approx \tan \alpha_{S t}\right)$, this simplifies to

$$
F_{T}=F_{R}+F_{L}
$$

\subsection{Research Methodology}

Figure 1 below shows the methodology flow chart that has been used as a guideline for this research in order to achieve the objectives.

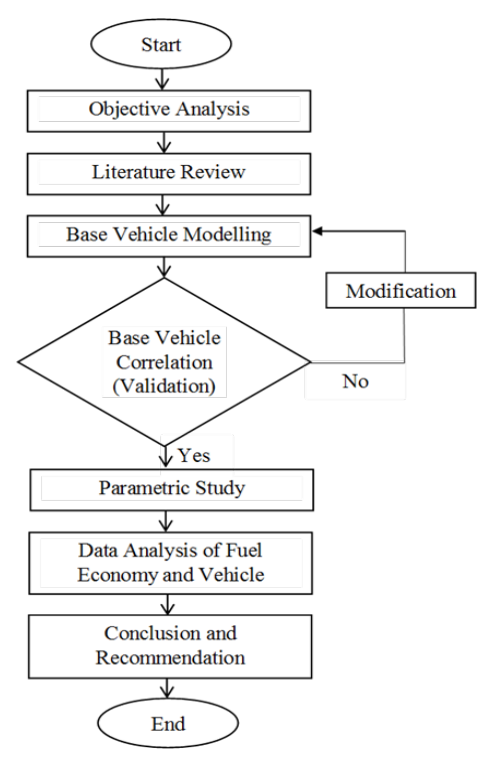

Fig. 1 - Methodology flowchart 


\subsection{Vehicle Modelling in GT-Suite}

For this study, a complete vehicle model is designed and develop in order to optimize and reduce fuel consumption. Figure 2 shows the full schematic vehicle model that was designed and developed in GT-SUITE. By using the virtual method, the quality and efficiency of a vehicle can be improved efficiently and accurately. An important tool is the simulation of the entire vehicle behaviour [14]. This vehicle model has been run using two cases which is NEDC Cycle in order to obtain its fuel consumption and $0-100 \mathrm{~km} / \mathrm{hr}$ to obtain the performance of the vehicle. The vehicle used as a base vehicle model in this study is a PROTON Saga 1.3L 4-AT. In this study, the model is intended to support development work, during which the comprehension of the entire vehicle and the interaction between subsystems is necessary [15]. Therefore, the values/data and key information such as gearbox, torque converter, clutch and brakes of the components were acquired from PROTON itself other than from PROTON catalogue and portal.

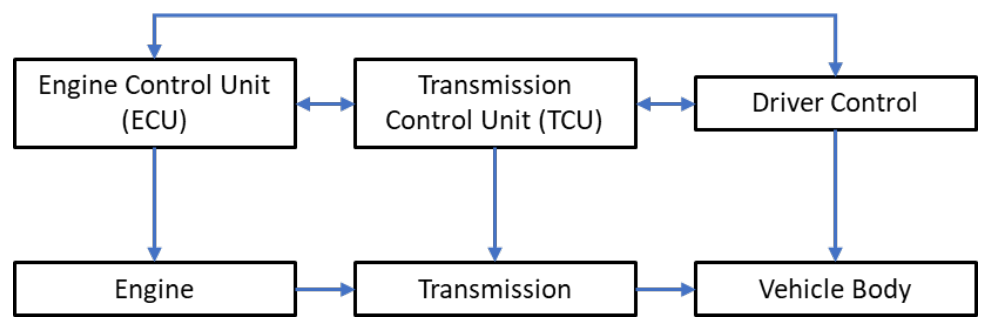

Fig. 2 - Full schematic vehicle model designed and developed in GT-SUITE

Engine - Engine is the crucial component for a vehicle to operate. The engine block in the vehicle model is a mapbased model which requires several engine maps along with engine and fuel specifications. The required engine maps in this study are mechanical output map, engine friction map and fuel consumption map. In order to ensure that the base model developed in this study is correlated with the actual vehicle, the details of required engine maps were provided by PROTON Engineering Department.

Optimized Parameter - The value of each parameter used in this study were obtained from the benchmarking process where some review and research has been done to collect the data from any catalogue and official website of the vehicle's brand that are available in Malaysia and in the same segment as the base model vehicle. A study based on the EPA fuel economy test found a 10\% reduction in weight resulted in 6-7\% fuel economy improvement, whereas a $10 \%$ reduction in rolling resistance or aerodynamic drag resulted in a $2 \%$ improvement [16].

Weight - The first parameter to be optimize is vehicle weight since it affects the engine power required to moves the vehicle. In this study, the vehicle weight was reduced in a uniform scale of $50 \mathrm{~kg}$ and the fuel consumption corresponds to the weight decrements were recorded and observed. The range of vehicle weight that has been used in this study is from $1075 \mathrm{~kg}$ which is the initial weight of the base model vehicle until $875 \mathrm{~kg}$.

Aerodynamic- The second parameter of the vehicle that will be optimize is the aerodynamic drag. Aerodynamic is one of the key players for the fuel consumption reduction since the frontal area of a vehicle directly influence the aerodynamic drag. In this study, the aerodynamic drag of a vehicle is reduced uniformly by 0.01 within the range of 0.33 until 0.27 .

Rolling Resistance - Reduction of a 10\% rolling resistance of a vehicle could lead to a range of 6-7\% of fuel consumption [17]. The rolling resistance is primarily affected by the vehicle's tyres when they roll over the road surface. The rolling resistance reduction in tyres was planned to decrease by $2 \%$ from its initial rolling resistance value. In this study, the rolling resistance is in the range of 0.010300 until 0.007542 since the minimum reduction that could be made is only up to $10 \%$.

Drivetrain Configuration - Drivetrain configuration which is the third parameter to be optimize also contribute to the decrement of fuel consumption. However, the improvement of the performance of a vehicle is always moving towards the opposite direction with the final gear ratio improvement. As the final gear ratio decrease, the time taken for a vehicle to accelerate from 0 to $100 \mathrm{~km}$ or commonly known as $0-100 \mathrm{~km} / \mathrm{h}$ will increase. Therefore, the most suitable final gear ratio that will be chosen in this study will be considered according to two important factors which are 0$100 \mathrm{~km} / \mathrm{h}$ and fuel consumption. The final gear ratio decrement in this study is starting from 4.121 until 3.700, with a scale of 0.10 . 
Idle Speed - The next parameter is idle speed since a vehicle at idle consumes the amount of fuel, although it does not been used to propel the vehicle. A higher idle speed means that the vehicle consumes more fuel at idle which in the end will cause waste. Thus, the idle speed will be reduced by 30rpm in the range of 750rpm which is the original rpm of the base vehicle model until 600rpm.

\subsection{Result and Discussion}

In this section, the result of the vehicle optimization in term of fuel consumption and performance will be discussed. In order to choose the most suitable value for each parameter to achieve the target which is $6.0 \mathrm{~L} / 100 \mathrm{~km}$, an individual simulation was run for each parameter with a different value which is known as the benchmark. As for the overall optimization process, the base vehicle model was optimized one by one parameter starting from weight optimization until stop-start. The table below shows the correlation between the base vehicle model and the actual vehicle of PROTON Saga 1.3L 4-AT. Table 2 shows the base model correlation that has been made where the correlation for fuel consumption is $0.15 \%$ and $0-100 \mathrm{~km} / \mathrm{h}$ is $2.22 \%$. The percentage error of the fuel consumption and $0-100 \mathrm{~km} / \mathrm{h}$ for the base vehicle model and the actual vehicle is less than $4 \%$, so it can be concluded that the vehicle model is valid.

Table 2 - Base model correlation

\begin{tabular}{ccccc}
\hline No. & Parameter & Actual Vehicle & $\begin{array}{c}\text { Base Vehicle } \\
\text { Model }\end{array}$ & Percentage Error \\
\hline 1. & Fuel consumption $(\mathrm{L} / 100 \mathrm{~km})$ & 6.80 & 6.79 & $0.15 \%$ \\
2. & $0-100 \mathrm{~km} / \mathrm{hr}(\mathrm{s})$ & 13.5 & 13.2 & $2.22 \%$ \\
\hline
\end{tabular}

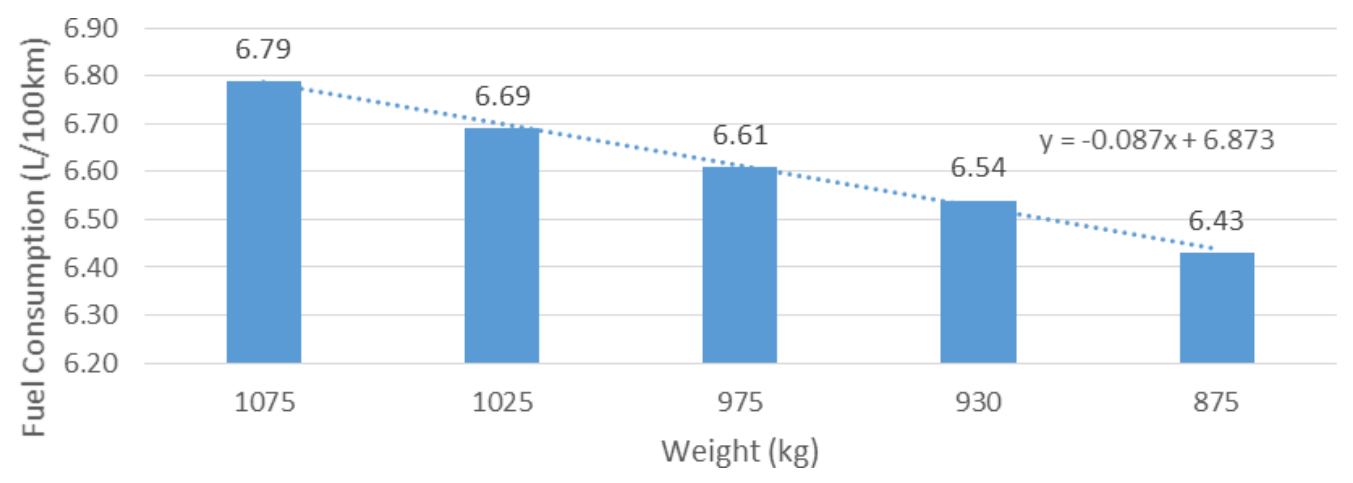

Fig. 3 - Effects of weight optimization on fuel consumption

Often, weight reduction is widely recognized as a cost-effective way to reduce the fuel consumption of a vehicle. However, it does not always give as a priority to be optimized compare to other vehicle characteristics. The NEDC reports that approximately a $0.6 \%$ reduction is achieved for each $1 \%$ saving in total vehicle mass [18]. It is worth to reduce the vehicle weight since a vehicle needs to overcome its inertial forces first in order for it to start moving or accelerate. In detail, the vehicle weight is linearly proportional to the power required to overcome the inertial forces, which means that a greater power is needed to overcome the forces if the vehicle weight is greater. Therefore, the fuel consumption could be reduced by reducing the engine power requirement vehicle of a vehicle which in other words, means reducing the vehicle weight. Figure 3 shows the effects of weight optimization on fuel consumption that has been done to the vehicle model according to the benchmark. The curb weight of the base vehicle model that was designed and produced by PROTON is $1075 \mathrm{~kg}$ which is quite heavier compared to other Sedan B-Segment vehicle. A huge decrement of $0.07 \mathrm{~L} / 100 \mathrm{~km}-0.10 \mathrm{~L} / 100 \mathrm{~km}$ of fuel consumption is observed due to the reduction of vehicle weight. It could be predicted that the decrement trend of fuel consumption will continue as the value of weight decrease. Therefore, it can be concluded that every $50 \mathrm{~kg}$ reduction of vehicle weight, the fuel consumption will be reduced approximately $0.09 \mathrm{~L}$ for every $100 \mathrm{~km}$ travel distance. 


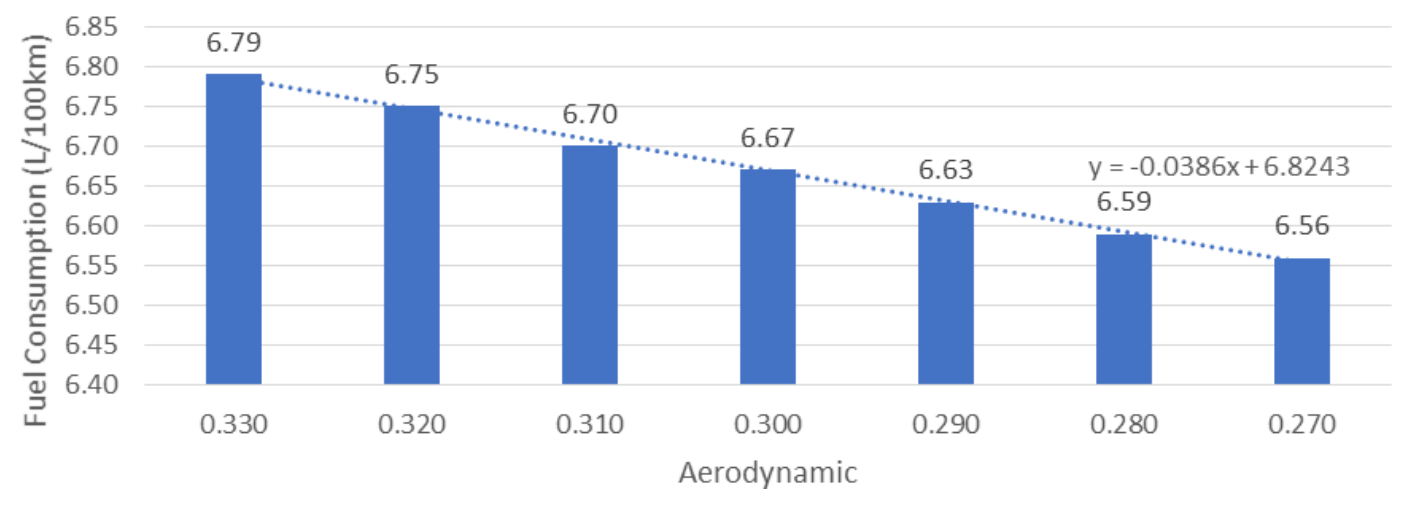

Fig. 4 - Aerodynamic optimization and fuel consumption

Aerodynamic drag reduction also offers an opportunity to reduce the consumption of fuel for a vehicle. However, the reductions in aerodynamics drag are seen to be less effective at reducing fuel consumption compare to weight reduction method. Typically, 35\% of the energy in a vehicle is used to overcome the aerodynamic drag in order to accelerate. The fuel consumption of a vehicle is affected by the relation of the surface of the vehicle and the air flowing through it. When a vehicle moves at higher speed, a vehicle with better aerodynamic could offer the least consumption of fuel through the improvement of crosswind stability. Aerodynamic optimization that was done to the vehicle model is shown in Figure 4. The reduction of aerodynamic value is a successive reduction of 0.01 from the initial aerodynamic value of PROTON Saga 1.3L 4-AT which is 0.33 . From the graph, it could be observed that there are quite a massive decrement of $0.03 \mathrm{~L} / 100 \mathrm{~km}-0.05 \mathrm{~L} / 100 \mathrm{~km}$ of fuel consumption as the value of aerodynamic decrease by 0.01 . The graph trend line shows that the fuel consumption will keep decreasing correspond to the trend line as the value of aerodynamic decrease. Therefore, it can be concluded that every 0.03 reduction of vehicle aerodynamic could lead to a reduction of $0.12 \mathrm{~L} / 100 \mathrm{~km}$ fuel consumption for this vehicle.

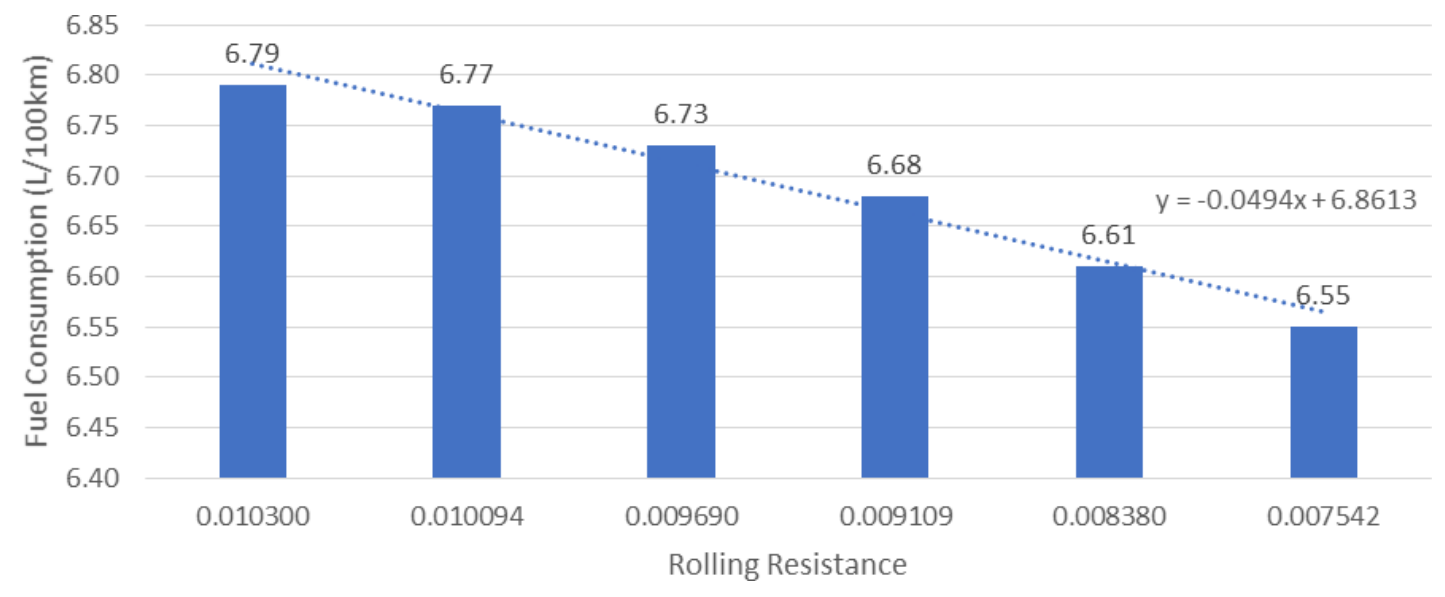

Fig. 5 - Rolling resistance optimization

Other than that, reducing the rolling resistance can also provide a very cost-effective way to reduce the energy use at once improve the fuel economy. It is because there are a lot of low rolling resistance tyres available on the market now nowadays with an average cost that is approximate to the standard tyres. Figure 5 shows the rolling resistance optimization that was done to the vehicle model in order to study the effect of rolling resistance on fuel consumption. Similar to the aerodynamic drag, the rolling resistance value also is a successive reduction of $2 \%$ from its initial value which is 0.010300 . The rolling resistance optimization shows the greatest reduction of fuel consumption which is around $0.02 \mathrm{~L} / 100 \mathrm{~km}-0.07 \mathrm{~L} / 100 \mathrm{~km}$ compare to other parameters which offers reduction less than $0.5 \mathrm{~L} / 100 \mathrm{~km}$ for each value. A significant drop in the fuel consumption trend line could be observed as the rolling resistance value drop. This is due to the energy needed for the vehicle to overcome the rolling resistance is huge which is almost half. Therefore, it can be concluded that every $2 \%$ reduction of the vehicle rolling resistance from its initial value could cause $0.02 \mathrm{~L} / 100 \mathrm{~km}$ reduction of fuel consumption for this vehicle. 
As for drivetrain optimization, it is quite difficult to be optimized since there is an aspect that needs to be considered before choosing the right gear ratio. Changing the final gear ratio of a vehicle could directly affect its performance which is $0-100 \mathrm{~km} / \mathrm{hr}$ since the fuel consumption and performance is inversely proportional. Figure 6 above shows the influences of final gear ration on fuel consumption which shows the drivetrain optimization that was done to the vehicle model. It could be observed that the reduction in final gear ratio caused a little decrement in fuel consumption of the vehicle. The reduction of 0.071 which is from the initial gear ratio value of 4.121 to 4.050 , is seen to reduce the fuel consumption only by $0.02 \mathrm{~L} / 100 \mathrm{~km}$. The reduction of final gear ratio from each value only drops the fuel consumption in the range of $0.01-0.03 \mathrm{~L} / 100 \mathrm{~km}$. The graph trend line shows that the fuel consumption will keep decreasing correspond to the trend line as the value of the final gear ratio decrease. Therefore, it can be concluded that every 0.1 reductions of vehicle final gear ratio could lead to a reduction of $0.02 \mathrm{~L} / 100 \mathrm{~km}$ fuel consumption.

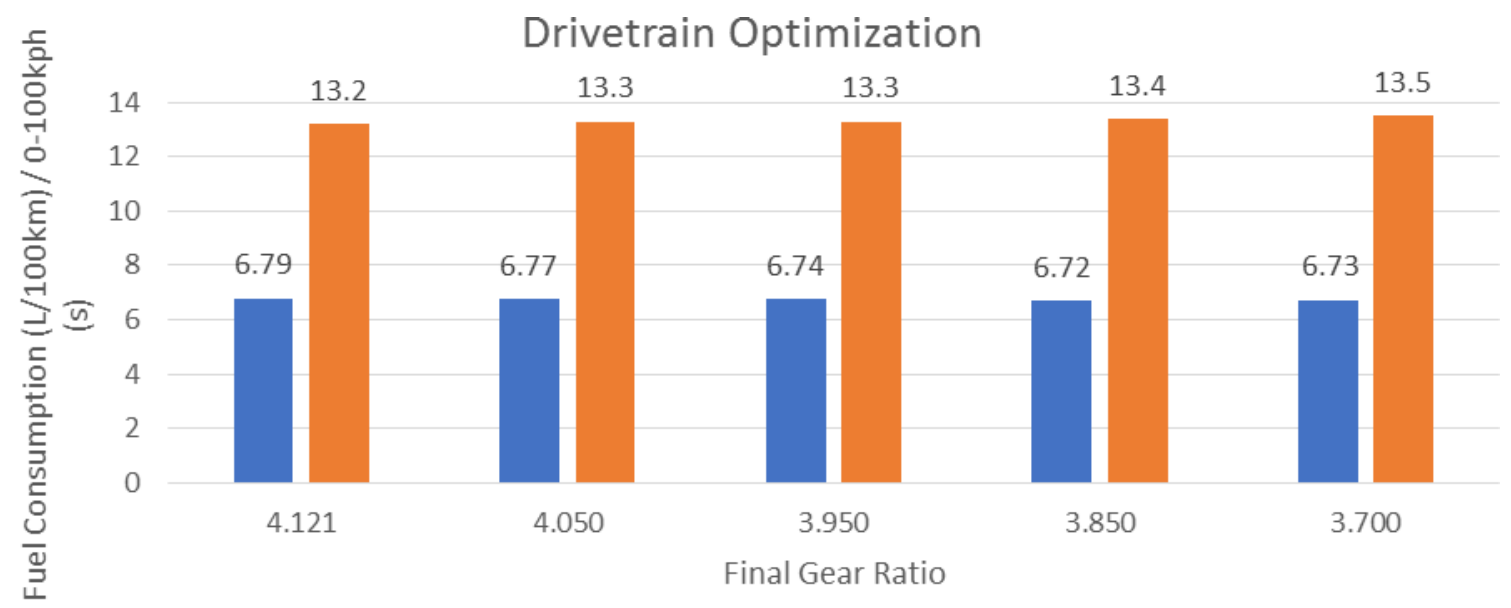

Fuel Consumption (L/100km)

0-100kph (s)

Fig. 6 - Influences of final gear ratio on fuel consumption

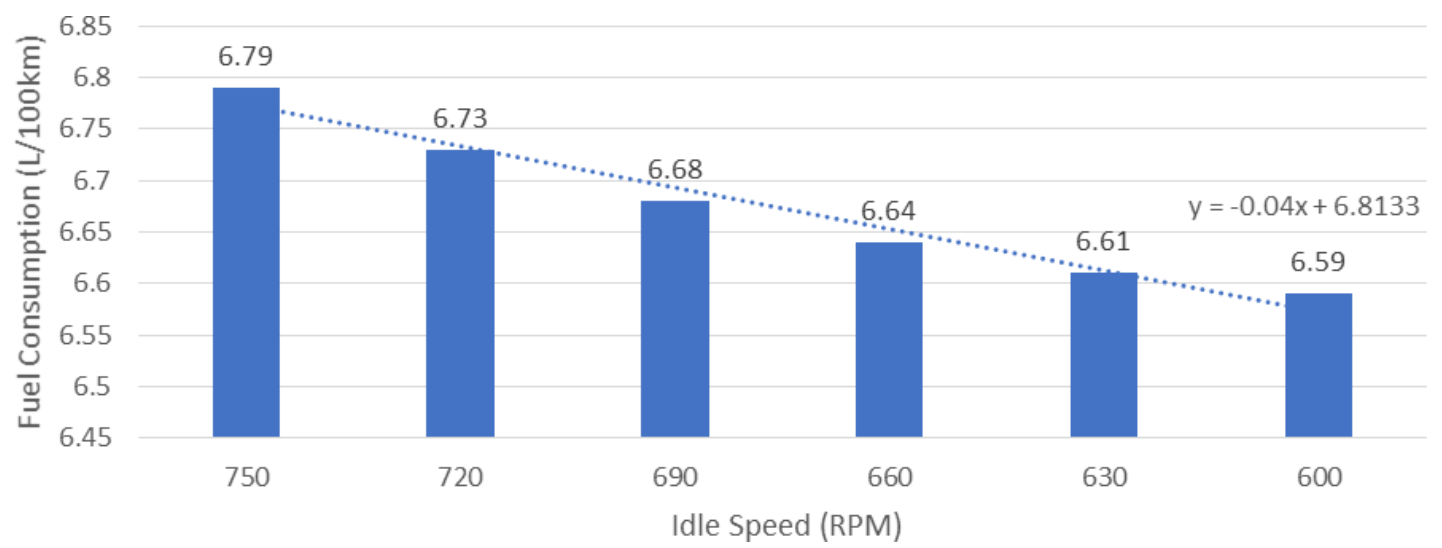

Fig. 7 - Effects of idle speed optimization on fuel consumption

A vehicle at idling consumed quite a lot of fuel without using the output power to move the vehicle which in turns become wasteful. A vehicle which idling for more than 10 seconds consumed more fuel compared to starting it. Other than that, the fuel consumed to just idling for 10 minutes is equal to the fuel needed to travel for 5 miles. Therefore, fuel consumption during idling should be reduced since it also contributes to emission. Figure 7 shows the effects of idle speed optimization on fuel consumption that was done to the vehicle model which started from the original idle speed value which is 750rpm. The reduction method for this idle speed optimization value is also similar to the rolling resistance and aerodynamics which is using the successive method. The idle speed value was reduced by $30 \mathrm{rpm}$ in order to observe the fuel consumption drop. However, this parameter is seen to show a constant and precise reduction in fuel consumption which is $0.02 \mathrm{~L} / 100 \mathrm{~km}-0.06 \mathrm{~L} / 100 \mathrm{~km}$ compared to the other parameter. The idle speed reduction trend line shows that fuel consumption could be reduced by if the idle speed of the vehicle continues to decrease. Therefore, it can be concluded that every $10 \mathrm{rpm}$ reduction of the vehicle rolling resistance from its initial value could cause $0.02 \mathrm{~L} / 100 \mathrm{~km}$ reduction of fuel consumption for this vehicle. 


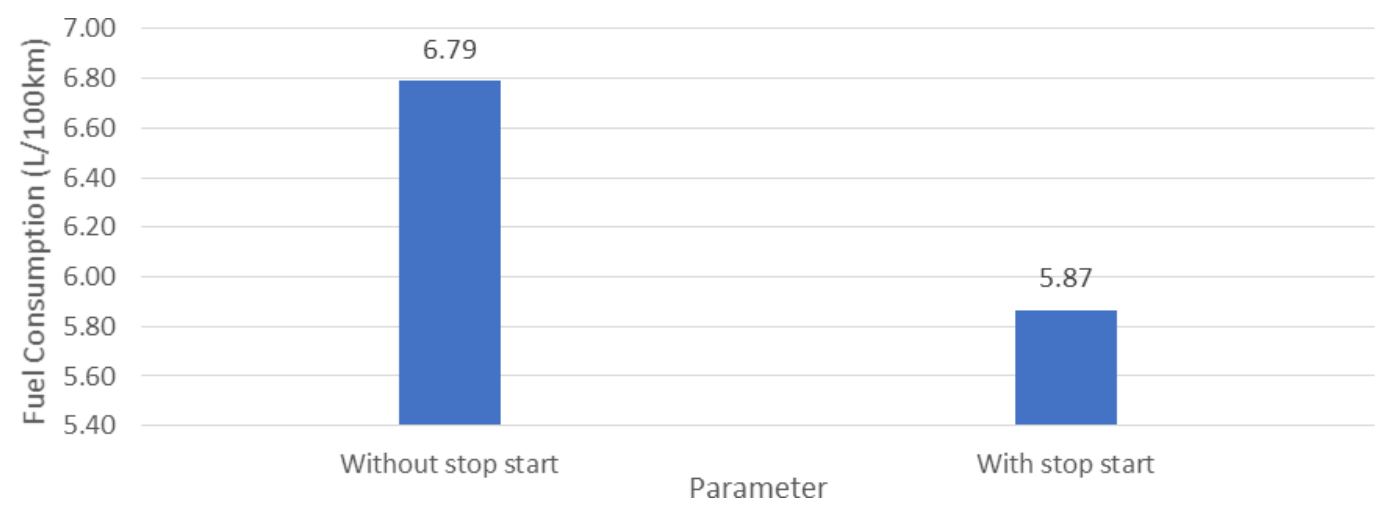

Figure 8 - Comparison of the without and with stop start system

Figure 8 shows the Comparison of the without and with the stop-start system. Driving in city traffic or heavily congested roads could cause a vehicle to consume a substantial amount of fuel idling when the vehicle is stopped. However, the stop-start system could offer the best solution to this problem. Stop-start system is capable of shutting down the vehicle engine when the vehicle is stopped, such as at traffic light. The system also offers a rapid engine restart for the vehicle launch. From the graph, the stop-start system is observed to give a considerable contribution in the aspect of fuel consumption reduction. The base vehicle model without implementing the stop-start system shows that the fuel consumption is $6.79 \mathrm{~L} / 100 \mathrm{~km}$. However, the same vehicle model that implementing the stop-start system shows a noticeable drop in fuel consumption which is $0.92 \mathrm{~L} / 100 \mathrm{~km}$, equivalent to $13.55 \%$ which only consume 5.87 $\mathrm{L} / 100 \mathrm{~km}$ of fuel.

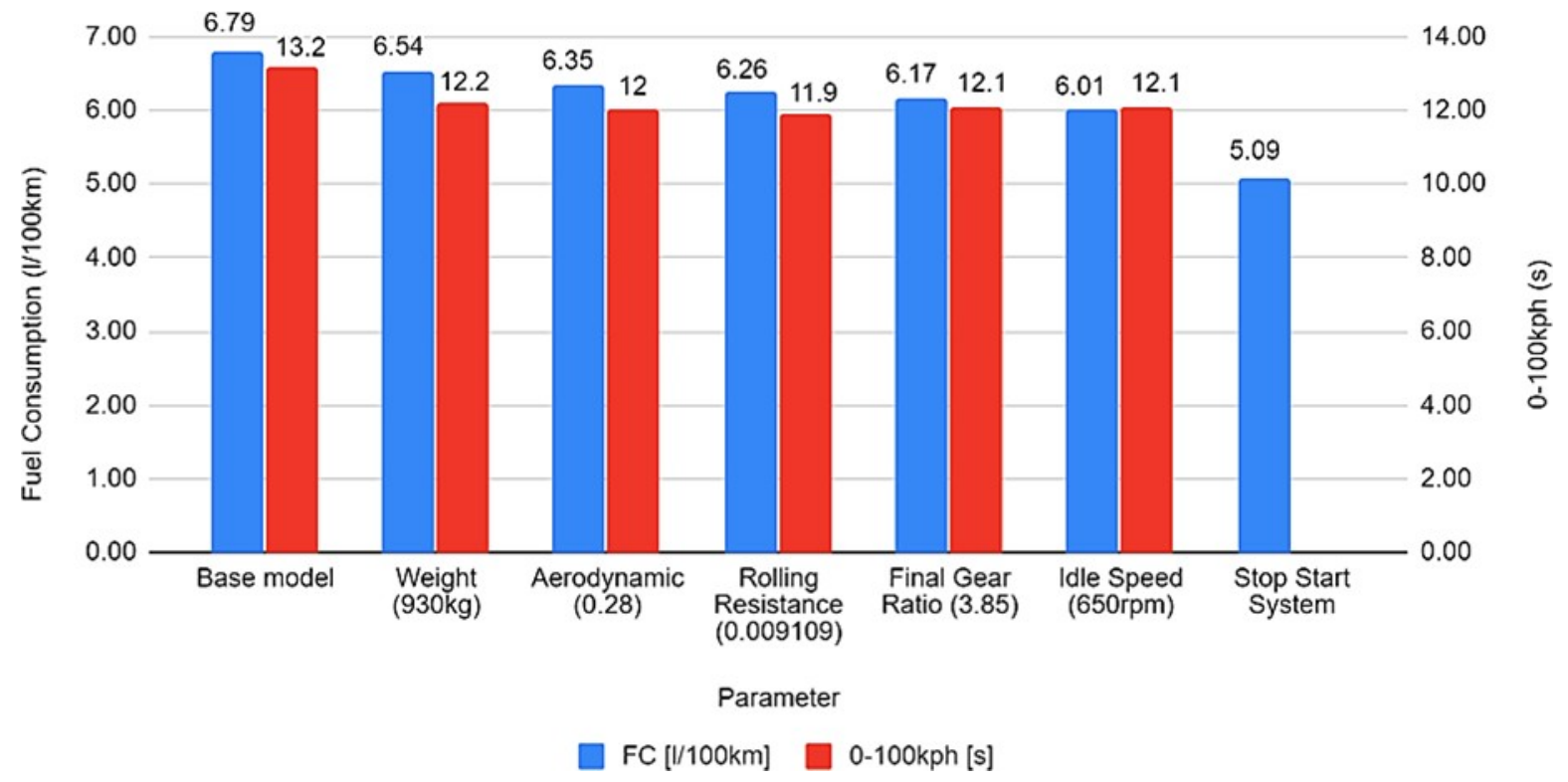

Fig. 9 - PROTON Saga 1.3L 4-AT Overall Optimization

Figure 9 shows the PROTON Saga 1.3L 4-AT Overall Optimization or also known as fuel walk. From the graph, the base vehicle model which is initially produced by PROTON is $6.79 \mathrm{~L} / 100 \mathrm{~km}$ with $0-100 \mathrm{~km} / \mathrm{h}$ of $13.5 \mathrm{~s}$. In order to reduce the fuel consumption, a big contributor to fuel consumption which is vehicle weight was optimized. In this study, the weight of the vehicle is reduced from $1075 \mathrm{~kg}$ to $930 \mathrm{~kg}$ and it shows a significant decrement in fuel consumption. A $0.25 \mathrm{~L}$ of fuel consumption drops was observed from $6.79 \mathrm{~L} / 100 \mathrm{~km}$ to $6.54 \mathrm{~L} / 100 \mathrm{~km}$ proved that vehicle weight plays an important role in fuel consumption. The drops in vehicle weight also resulted in $1.3 \mathrm{~s}$ improvement of $0-100 \mathrm{~km} / \mathrm{h}$ from $13.5 \mathrm{~s}$ to $12.2 \mathrm{~s}$ The value of $930 \mathrm{~kg}$ vehicle weight was chosen because it is the optimum value to reach the $6.0 \mathrm{~L} / 100 \mathrm{~km}$ fuel consumption target since the project is in 2019 . In order to reduce a large amount of weight, many parts of the vehicle body and components should be replaced and upgrade. Therefore, a greater reduction in term of vehicle weight is quite difficult since it needed a long-time duration to design a new body.

The next optimization that has been made is aerodynamic drag reduction which is from 0.330 to 0.280 . The aerodynamic is directly influenced by the design and surface of the vehicle body. Therefore, it is important to ensure that there is no major change must be made to the vehicle body since it involved a lot of costs to design and produce a 
totally new body. In order to achieve 0.280 aerodynamic drag of the vehicle, it only involves some minor change to the vehicle body and does not require a high cost. By using a 0.280 aerodynamic drag, the fuel consumption decreases from $6.54 \mathrm{~L} / 100 \mathrm{~km}$ to $6.35 \mathrm{~L} / 100 \mathrm{~km}$ and $0.2 \mathrm{~s}$ decrement in $0-100 \mathrm{~km} / \mathrm{h}$ from $12.2 \mathrm{~s}$ to $12.0 \mathrm{~s}$. After that, the rolling resistance was optimized to continue the fuel walk. According to NAP, there is no specific standard to measure the rolling resistance of a tire. Therefore, the value of rolling resistance is calculated based on a $2 \%$ reduction from its initial value in order to achieve the target. Rolling resistance is a cost-effective method to reduce fuel consumption since replacing a tire does not consume a lot of costs [13]. Currently, the vehicle is using the Silverstone Synergy M3 tire with a 0.0103 rolling resistance. In order to achieve the rolling resistance of 0.009109 which is the best rolling resistance, the tire should be changed to BF Goodrich Long Trail T/A. Thus, the fuel consumption will continue to drop from $6.35 \mathrm{~L} / 100 \mathrm{~km}$ to $6.26 \mathrm{~L} / 10 \mathrm{~km}$. As the fuel consumption decrease due to low rolling resistance, the performance of the vehicle also increases when $0-100 \mathrm{~km} / \mathrm{h}$ is seen to decrease from $12.0 \mathrm{~s}$ to $11.9 \mathrm{~s}$.

The optimization sequence then continues with drivetrain configuration optimization which is the final gear ratio. It is essential to choose the best value for the final gear ratio since it affects the engine performance. In order to identify the best final gear ratio, the performance of $0-100 \mathrm{~km} / \mathrm{h}$ and fuel consumption should be considered. In this study, the value of gear ratio is chosen according to the best reduction in the term of fuel consumption which is $1.44 \%$ in order to achieve the target and the acceptable value of $0-100 \mathrm{~km} / \mathrm{h}$ performance which is only $1.50 \%$ reduction. Therefore, the fuel consumption shows a decrement from $6.26 \mathrm{~L} / 100 \mathrm{~km}$ to $6.17 \mathrm{~L} / 100 \mathrm{~km}$ meanwhile, the $0-100 \mathrm{~km} / \mathrm{h}$ shows an increment in term of time taken from $11.9 \mathrm{~s}$ to $12.1 \mathrm{~s}$. As for the idle speed, the fuel consumption is observed to decrease from $6.17 \mathrm{~L} / 100 \mathrm{~km}$ to $6.01 \mathrm{~L} / 100 \mathrm{~km}$ due to its implementation. However, the $0-100 \mathrm{~km} / \mathrm{h}$ does not show any difference in this parameter optimization since the vehicle does not move during idle speed. In order to ensure that the vehicle does not stall during idling, the idle speed must be within the range which is from 600rpm - 1000rpm. The value of 650rpm is chosen since it does not extremely low that could lead to an engine stall and enough to achieve the target. The last optimization is the stop-start system. However, the stop-start system is not included in the optimization to achieve the goal due to its barrier to be implemented in a short time. In order to perform a stop-start operation, a huge cost investment has to be done to set up the system which consumes a long time. Other than that, the arrangement of the engine compartment also needs to be changed in order to add on some components such as a battery. Therefore, the stop start system will be a long-term alternative step to reduce the fuel consumption significantly.

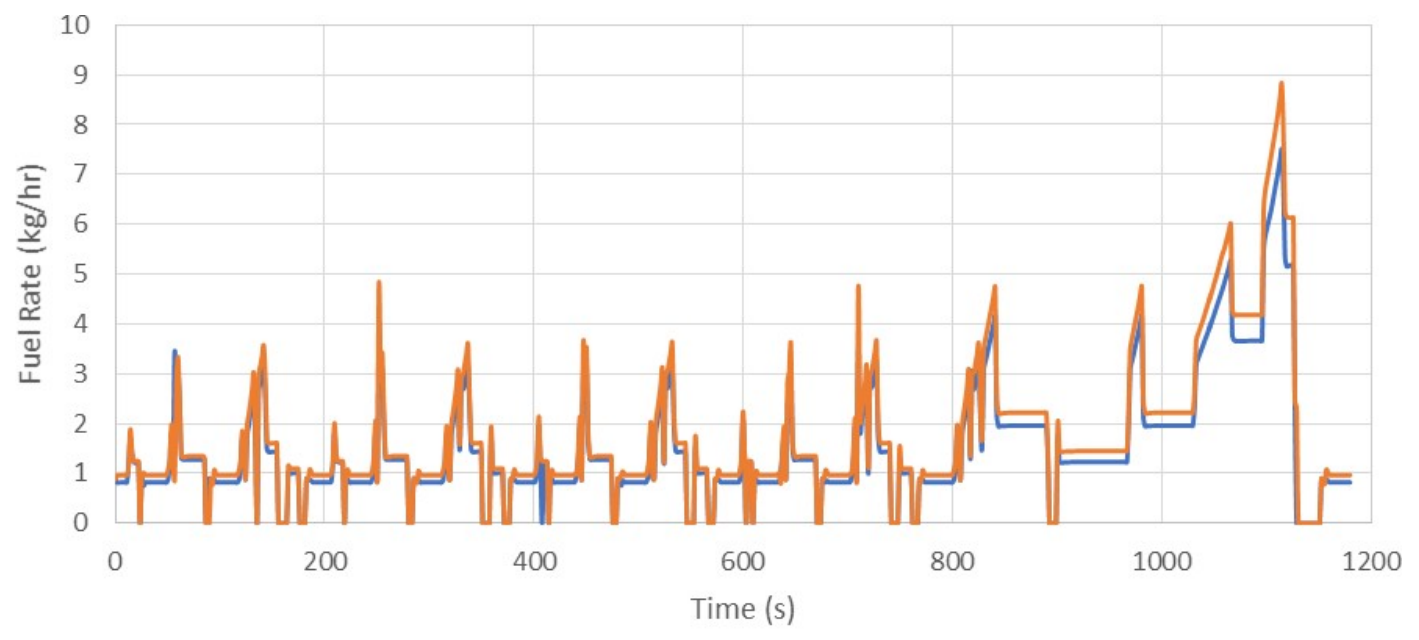

- Optimized Model — Base Model

Figure 10 - Engine Consumption Rate of PROTON Saga 1.3L 4-AT

Figure 10 above shows the engine consumption rate of PROTON Saga 1.3L 4-AT. Basically, NEDC cycle graph which consists of $1180 \mathrm{~s}$ of fuel rate consumption of a vehicle. From the graph, there are two different cycles which is base vehicle model fuel consumption rate and optimized model fuel consumption rate. It can be observed that the fuel consumption rate of the base model is higher compared to the optimized model. As a result of vehicle optimization that was done, the fuel consumption for this vehicle decrease from $6.80 \mathrm{~L} / 100 \mathrm{~km}$ to $6.01 \mathrm{~L} / 100 \mathrm{~km}$ with a difference of 0.79 $\mathrm{L} / 100 \mathrm{~km}$ which is equivalent to $11.62 \%$. 


\subsection{Conclusion}

In a nutshell, the 1-Dimensional 4-AT vehicle model for fuel economy and performance analysis was successfully designed and developed. In addition, the vehicle model was also successfully evaluated and optimized in achieving the product target and legislation requirements. The base model fuel consumption for this vehicle is 6.79 $\mathrm{L} / 100 \mathrm{~km}$ with $0.15 \%$ difference with actual vehicle model which is $6.80 \mathrm{~L} / 100 \mathrm{~km}$ meanwhile the $0-100 \mathrm{~km} / \mathrm{h}$ having a $2.22 \%$ difference where the vehicle model is $13.2 \mathrm{~s}$ while the actual vehicle is $13.5 \mathrm{~s}$. Overall optimization improvement that was made on PROTON Saga 1.3L 4-AT. After optimization without implementing the stop-start system, the vehicle model able to achieve $11.62 \%$ of fuel consumption reduction where the final result is $6.01 \mathrm{~L} / 100 \mathrm{~km}$ which is having a slight difference with the target that should achieve $6.00 \mathrm{~L} / 100 \mathrm{~km}$. As for the $0-100 \mathrm{~km} / \mathrm{h}$, the time taken after optimization is much better when it has shown a definite improvement of $11.57 \%$ where the time is taken drops from $13.2 \mathrm{~s}$ to $12.1 \mathrm{~s}$. It could be concluded that the target is achieved since the value of deviation is too small which $0.17 \%$ is. On the other hand, the model would achieve a bigger fuel consumption decrement with the implementation of a stopstart system where it could reduce up to $25.03 \%$ with the new fuel consumption of $5.09 \mathrm{~L} / 100 \mathrm{~km}$. Through this study, PROTON Saga 1.3L 4-AT fuel consumption could be reduced to the target value which is $6.0 \mathrm{~L} / 100 \mathrm{~km}$ in order to be in the EEV certified vehicle range that was set by the NAP 2014 to stay competitive in the market and fulfil the ASEAN emission legislation target. Yet, there are some challenges that need to be faced to ensure the success of improving the fuel economy of this vehicle. The first challenge was the uncomfortability of passengers seating as a result of drag force reduction through reducing the vehicle's width, and height since reducing those parameters could affect the frontal area. In addition, reducing the air drag also could affect the airflow in the frontal area and leads to lesser cooling efficiency in radiator and intercooler. Moreover, it is also a challenge to maintain the stability and reducing rattling noise of the vehicle during high-speed driving. During rain or wet climatic condition, the traction effect reduction could give a worse impact to braking distance and skidding. In order to ensure that this study will and provides a more significant contribution and impact towards reducing fuel consumption and improving performance, some future works are recommended. The integration of lubricants, ETM, HVAC and vehicle cooling, are crucial to ensure more effective impacts towards the fuel economy and emission. Other than that, implementing hybrid powertrain such as adding the stop-start system to the vehicle through Mild Hybrid Electric Vehicle (MHEV) configuration is also one of the crucial key player in reducing fuel consumption and emission for a long-term effect even though its installation is cost consuming.

\section{Acknowledgement}

The authors would like to thank the Ministry of Education Malaysia for supporting this research under Fundamental Research Grant Scheme Vot No. FRGS/1/2019/TK10/UTHM/02/10 and partially sponsored by Universiti Tun Hussein Onn Malaysia.

\section{References}

[1]. Z. Yang and A. Bandivadekar, "Light-Duty Vehicle Greenhouse Gas and Fuel Economy Standards,” 2017.

[2]. Khalid, A., Nursal, R.S., Jacob, D.W., Jaat, N., Sunar, N.M., Amirnordin, S.H. "Effect of ambient temperature on ignition delay, combustion process and emission of biodiesel derived from algae", International Journal of Integrated Engineering, 10 (4), pp. 43-48. 2018

[3]. Andsaler, A.R., Khalid, A., Jaat, N. "Simulation and modeling of mixture formation under variant ambient condition and injection pressure of biodiesel spray”, International Journal of Integrated Engineering, 9 (3), pp. $18-23,2017$

[4]. Khalid, A., Tajuddin, A.S.A., Jaat, N., Manshoor, B., Zaman, I., Hadi, S.A.A., Nursal, R.S.'Performance and emissions of diesel engine fuelled with preheated biodiesel fuel derived from crude palm, jatropha, and waste cooking oils",International Journal of Automotive and Mechanical Engineering, 14 (2), pp. 4273-4284.2017

[5]. "ASEAN Fuel Economy Roadmap for Transport Sector 2018 - 2025: with Focus on Light-Duty Vehicles," Jakarta, 2019. ISBN 978-602-5798-32-0

[6]. Malaysian Automotive Association . "National Automotive Policy (NAP) 2014". Retreived on, 8. 2014

[7]. H. Naunheimer, B. Bernd, R. Joachim, and N. Wolfgang, “Automotive Transmission”, Second Edi. London New York: Springer Heidelberg Dordrecht, 2011.

[8]. Naunheimer, H., Bertsche, B., Ryborz, J., \& Novak, W. Automotive Transmissions. Fundamentals, Selection, Design and Application. Heidelberg, Dordrecht. 2011

[9]. M. Guillou and C. Bradley, "Fuel Consumption Testing to Verify the Effect of Tire Rolling Resistance on Fuel Economy," 2018.

[10]. J. Ejsmont, S. Taryma, and G. Ronowski, "Influence of Load and Inflation Pressure on the Tyre Rolling Resistance," Int. J. Automot. Technol., vol. 17, no. 2, pp. 237-244, 2016.

[11]. R. Khanger and A. Bardhan, "Challenges in Developing Low Rolling Resistance Tyre,” 2018. 
[12]. M. N. Sudin, M. A. Abdullah, S. A. Shamsuddin, F. R. Ramli, and M. Mohd, "Review of Research on Vehicles Aerodynamic Drag Reduction Methods," no. February 2016, 2014.

[13]. Jazar, R. N.. Vehicle dynamics: theory and application. Springer.2017

[14]. S. K. Mallikarjunappa, "Vehicle Fuel Economy \& Performance Modelling with Focus on an Engine,"

[15]. Asfoor, M. S., \& Beyerlein, S. (2014). Use of GT-suite to study performance differences between Internal Combustion Engine (ICE) and Hybrid Electric Vehicles (HEV) powertrains. Journal of the Idaho Academy of Science, 50(1), 88-89. 2018

[16]. I. E. A. Etsap and T. Brief, “Automotive Weight and Drag Reduction,” January, pp. 1-7, 2011.

[17]. G. Sivaraj, K. M. Parammasivam, and G. Suganya, "Reduction of Aerodynamic Drag Force for Reducing Fuel Consumption in Road Vehicle using Basebleed," vol. 11, no. 6, pp. 1489-1495, 2018.

[18]. Fontaras, G., Zacharof, N. G., \& Ciuffo, B . "Fuel consumption and CO2 emissions from passenger cars in Europe-Laboratory versus real-world emissions". Progress in Energy and Combustion Science, 60, 97-131. 2017 